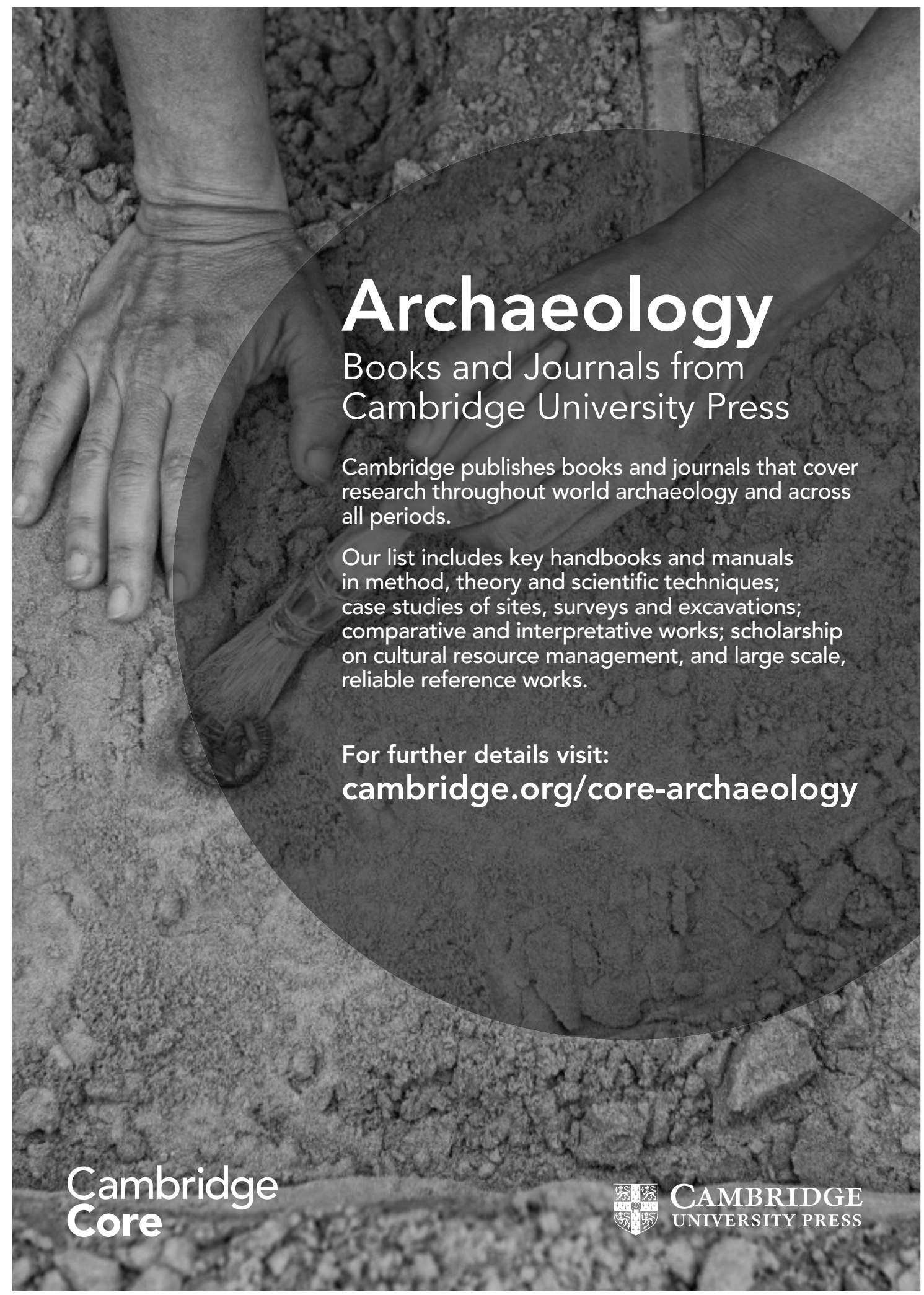




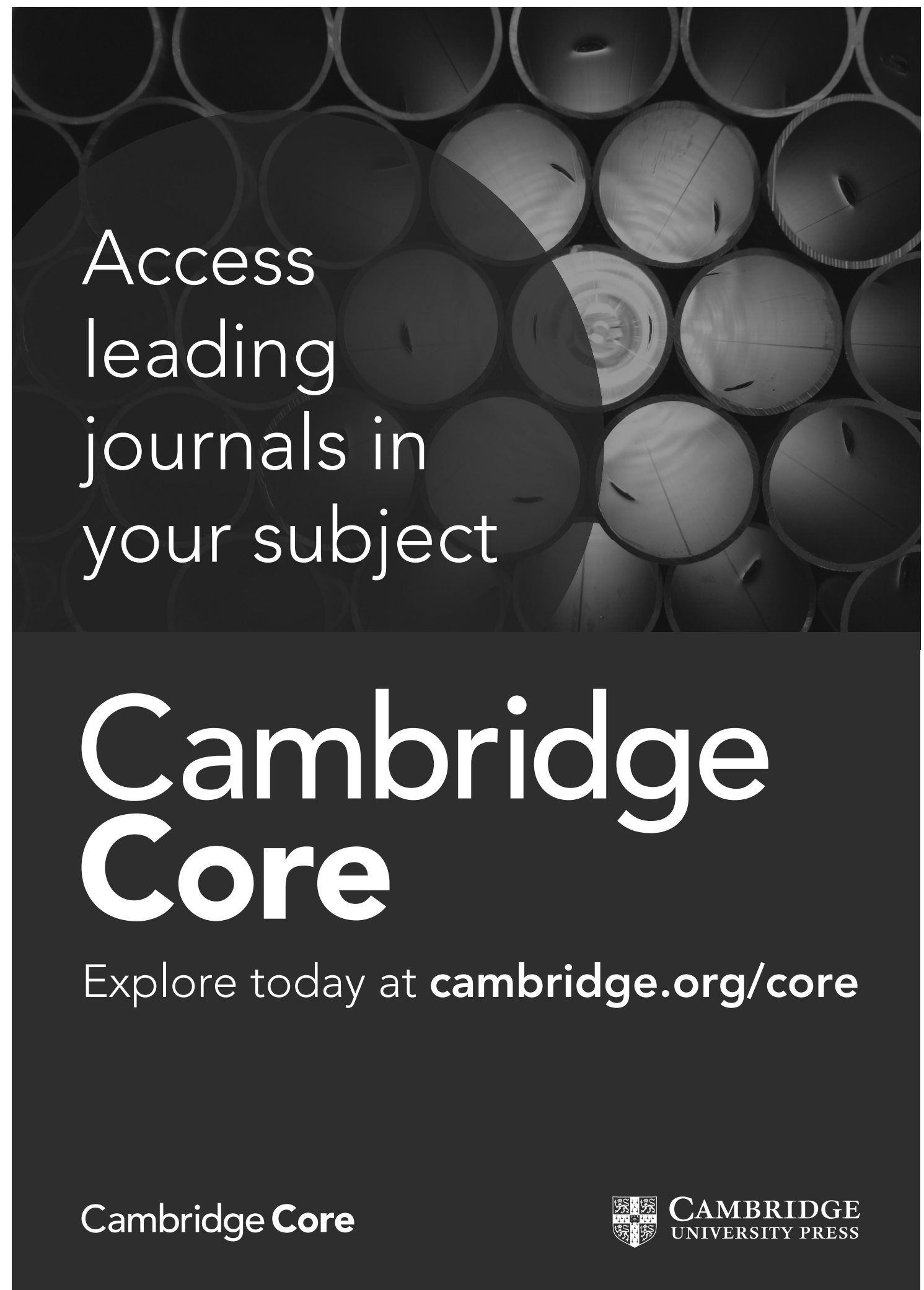




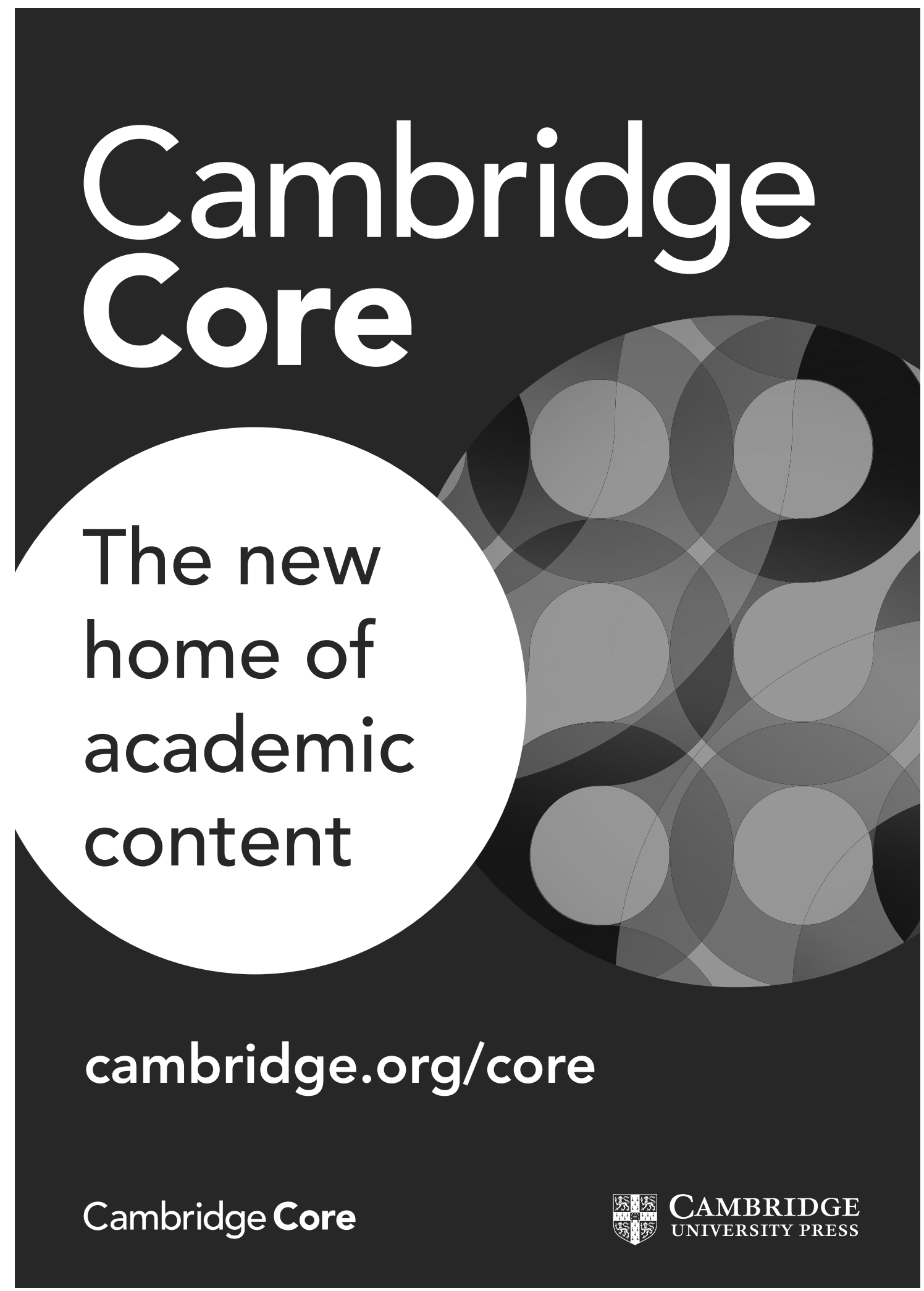




\section{Notes for Contributors}

The Cambridge Archaeological Journal (ISSN 0959-7743) was founded in 1991 as one of the key initiatives of the McDonald Institute for Archaeological Research. It has come to be recognized as one of the leading journals in archaeological theory. CAJ is published four times a year in February, May, August and November with articles available online earlier in many cases. It is indexed in all major journal indexes. All articles in CAJ are peer-reviewed; peer review is usually completed within two months from submission.

CAJ supports Open Access to journals under the policies of our publisher, Cambridge University Press (cambridge.org/core/ services/open-access-policies). Our "Green" Open Access policy means that the final accepted manuscript can be freely circulated via an institutional web page or repository with no embargo period. Our "Gold" Open Access policy is that articles can be freely circulated in all ways, including via the Cambridge University Press website for the journal, upon payment of a one-off article processing charge. CAJ's Open Access policy is fully compliant with UK and international government and granting body requirements.

Area and remit

CAJ covers significant archaeological research, both theoretical and descriptive. We are keen to receive articles and other material that deals with broadly-defined social, symbolic and cognitive issues such as art and iconography, burial and ritual, social process and change, the meaning of material culture, representations and symbolism, and the evolution of human cognition. We aim to promote research into these issues, and to provoke discussion and debate. Discussion features, debates, and thematic special sections are all possible formats for publication in CAJ.

CAJ has no restriction on period or place, and we are happy to receive material from any part of the world. Recently published papers have spanned the whole range of archaeology from the Lower Palaeolithic to contemporary archaeology and heritage issues, and from the Pacific to Central Asia, from Maya cities to Neolithic northwest Europe. We recognise that scholarship is international and we welcome manuscripts from authors whose first language is not English. Please note that CAJ has a broad, international readership: we usually ask that papers identify a general topic or theoretical issue to which they are relevant and are written to be understandable by people who are not specialised in the topic. Papers which are written in ways principally accessible to and of interest to area or period specialists are probably more suitable for regional or topical journals.

\section{Submissions}

All manuscripts should be submitted via CAJ's online submission system, which can be found at: mc.manuscriptcentral.com/caj

Submission of an article is taken to imply that it has not previously been published, and is not under consideration for publication elsewhere. Upon acceptance of a paper, the author will be asked to assign copyright (on certain conditions) to the McDonald Institute for Archaeological Research. Contributors are responsible for obtaining permission to reproduce any material in which they do not own copyright, to be used in both print and electronic media, and for ensuring that the appropriate acknowledgements are included in their manuscript.

Articles should normally be up to 10,000 words (including references); in exceptional cases, longer articles will be considered if their length is justified. An abstract of up to 180 words should be supplied. The affiliation and email address of each author should appear just before the references and a 50-word biography of each author specifying current academic position, subject interests and any relevant publications should be included after the bibliography.

All figures will be published online in colour; there is also provision for publishing some figures in colour in the print version. Papers submitted for review may include lower-resolution versions of figures either as separate files or embedded in the text. Figures for revised versions which have been accepted for publication should be submitted as individual high-quality digital files (preferably 600 dpi tiffs). There is some scope for including online supplementary material. For matters of style, prospective contributors should use the current issue of the Journal as a guide to preferred practice. Detailed guidelines are available at cambridge. org/core/journals/caj/information/instructions-contributors. Manuscripts may be submitted as written but, if accepted, must be converted to journal style before the article can go into production.

Offprints. Authors receive a complimentary pdf of their paper on publication. Offprints may be purchased if ordered at proof stage.

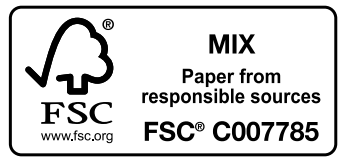

This journal issue has been printed on $\mathrm{FSC}^{\mathrm{TM}}$-certified paper and cover board. FSC is an independent, nongovernmental, not-for-profit organization established to promote the responsible management of the world's forests. Please see www.fsc.org for information. 


\section{CAMBRIDGE ARCHAEOLOGICAL JOURNAL}

\section{Volume 28 Number 3 August 2018}

\author{
John A. Hayward, \\ lain G. Johnston, \\ Sally K. May \\ and Paul S.C. Taçon \\ Christopher M. Watts \\ Martin Porr \\ Polly Schaafsma \\ Bradley T. Lepper, \\ James R. Duncan, \\ Carol Diaz-Granádos and \\ Tod A. Frolking \\ Marion Dowd \\ Minkoo Kim, Ranyeong Oh, \\ Moonbae Bang, \\ Jeong-Wook Rha and \\ Youjin Jeong \\ Barry Taylor
}

Anne van Duijvenbode

David Walsh

José Carlos de la Puente Luna

Christopher Witmore

Thomas J.T. Williams

Michael E. Smith

Daniel J. Pullen

Michael Loughlin

L. Antonio Curet

Sarah Craft

John Bennet

Thomas G. Garrison

Brent R. Fortenberry

Julie Zimmermann
Memorialization and the Stencilled Rock Art of Mirarr Country, Northern Australia

$361-378$

Counter-monuments and the Perdurance of Place

379-393

Country and Relational Ontology in the Kimberley, Northwest Australia: Implications for Understanding and Representing Archaeological Evidence

Human Images and Blurring Boundaries. The Pueblo Body in Cosmological Context: Rock Art, Murals and Ceremonial Figures

Arguments for the Age of Serpent Mound

$411-431$

$433-450$

Bewitched by an Elf Dart: Fairy Archaeology, Folk Magic and Traditional Medicine in Ireland

$451-473$

Rice and Social Differentiation on a Volcanic Island: An Archaeobotanical Investigation of

Yerae-dong, Korea

$475-491$

Subsistence, Environment and Mesolithic Landscape Archaeology

$493-510$

$511-512$

Colonized Bodies, Worlds Transformed. Towards a global bioarchaeology of contact and colonialism, edited by Melissa S. Murphy \& Haagen D. Klaus

Visual Conversations in Art and Archaeology: Images of Mitra, by Philippa Adrych, Robert Bracey, Dominic Dalglish, Stefanie Lenk \& Rachel Wood

Inka History in Knots: Reading khipus as primary sources, by Gary Urton

$512-513$

$514-515$

Traces of the Past: Classics between history \& archaeology, by Karen Bassi

$515-518$

The Anarchy: War and status in 12th-century landscapes of conflict, by Oliver H. Creighton \& Duncan W. Wright

The Aztec Economic World: Merchants and markets in ancient Mesoamerica, by Kenneth G. Hirth

$519-521$

The Collapse of the Mycenaean Economy: Imports, trade, and institutions 1300-700 BCE, by Sarah C. Murray

The Early Olmec and Mesoamerica: The material record, edited by Jeffrey P. Blomster \& David Cheetham

The Caribbean Before Columbus, by William F. Keegan \& Corinne L. Hofman

$525-526$

The Archaeology of Byzantine Anatolia: From the end of Late Antiquity until the coming of the Turks, edited by Philipp Niewöhner

Understanding Relations Between Scripts: The Aegean writing systems, edited by P.M. Steele

$528-530$

The Ancient Urban Maya: Neighborhoods, inequality, and built form, by Scott R. Hutson

$530-532$

Contemporary Archaeology and the City: Creativity, ruination, and political action, $\quad$ 532-534 edited by Laura McAtackney \& Krysta Ryzewski

Ritual and Archaic States, edited by Joanne Murphy

$534-535$

Corrigendum 